\title{
Application Research for Performance of Refrigeration Units with Flash Tank Economizer
}

\author{
Qin Huanghui ${ }^{1}$ and Fan $\mathrm{Li}^{1,2}$ \\ ${ }^{1}$ Department of Marine Engineering, Nantong Shipping College, Nantong, China \\ ${ }^{2}$ College of Ocean Science and Engineering, Shanghai Maritime University, Shanghai, China
}

\begin{abstract}
This paper studies the influence of flash economic system on performance of refrigeration unit using Refrigerant R290. Theoretical analyses of refrigeration system with flash type economizer are carried out firstly, which provide theoretical basis for working parameters. Under different evaporation temperature, influences of supply pressure on the refrigerating capacity and COP are studied and verified through experimental. Experimental results show that, using the economizer can effectively improve the cooling capacity and COP, and achieve the effect of saving energy. With the increase of supply pressure, refrigeration capacity of refrigerating unit and shaft power decreases gradually and the refrigeration coefficient rise first and then drop, to determine the best economic position.
\end{abstract}

\section{Introduction}

With the improvement of people's living standard and the development of industry, refrigerating units are widely used in the food, drinks, dairy products, petrochemical industry, coal, medicine, textile, paper making, tobacco, printing and other industries. The cooling temperature generally is between $-80^{\circ} \mathrm{C} \sim 0^{\circ} \mathrm{C}$. For example, there are cooling, cold storage, frozen food, ultra-low temperature frozen in the process of frozen food, in detail, $0^{\circ} \mathrm{C}$ for the cooling room, $-18^{\circ} \mathrm{C}$ for storage room, $-35^{\circ} \mathrm{C}$ for refrigerating room, $-30^{\circ} \mathrm{C} \sim-80^{\circ} \mathrm{C}$ for ultra-low temperature frozen. The lower the evaporation temperature of refrigerating unit, the greater the compression ratio, the sharp fall in the efficiency of compression. When compression ratio is greater than 8 to 10, two-stage refrigeration system should be used [1]. Refrigeration unit with economizer is a simplified twostage compression refrigeration cycle system, the refrigerating capacity and refrigeration coefficient can be improved. When the evaporation temperature is lower than $-30^{\circ} \mathrm{C} \sim-40^{\circ} \mathrm{C}$ and the compression ratio is greater than 8 or 10 , the effect is obvious. At present, there generally two types of economizer, they are flash type and sub-cooled type. The latter is safe and reliable, but the system is high cost and complex. And it is achieved by direct expansion. The former is simple in structure, easy to control and low in cost, so is mostly used in refrigeration unit [2].

When screw compressor works, the refrigerating capacity and the screw refrigeration coefficient can be increased by adding a new supply port at the rotor to draw in gas from the economizer [3], [4]. Yang Li, etc. from the Shanghai Jiao Tong University studied the performance of screw refrigeration compressor using R134a and R22 by numerical simulation, and compared the performance difference between economizer units and common refrigeration units [5]. Sun Zhen, etc. from the Shanghai Maritime University studied performance of screw refrigeration unit using R134a with ejector and economizer in different operating conditions, and optimized injection port working with economizer [6]. Sun Chao etc. from Huazhong University of Science and Technology took numerical analysis and study on R134a applying in gas supply on refrigeration system of screw compressor [7]. This paper studies the gas supply process of the refrigeration unit system with flash type economizer. The refrigerant is propane (R290), a kind of natural refrigerants [8].

Under different evaporation temperature, influences of supply pressure on the refrigerating capacity and COP are studied in this paper, and verified through experimental. This research has an important guiding significance for the design and application of refrigerating units with flash type economizer.

\section{Theoretical analysis}

Refrigeration system with flash type economizer is shown in Fig. 1. The LCV throttles the liquid refrigerant, some of the liquid refrigerant change into gas after passing this valve, and flow into the flash type economizer.

The opening of regulating valve- 4 is controlled by adjusting the liquid level in the condenser. Pressure control valve- 6 maintains the supply pressure in the flash type economizer. The flashed refrigerant gas enters the economizer port of the compressor, while the saturated 
liquid through the economizer piping flows into the low pressure evaporator by the second throttling valve. In the economizer, the flashed refrigerant gas enters into the primitive volume chamber (the suction chamber) after passing through the pressure control valve and the gas supply port in the screw compressor.

The flashed refrigerant gas and the gas in the primitive volume chamber are compressed together, so the compressor power will increase.

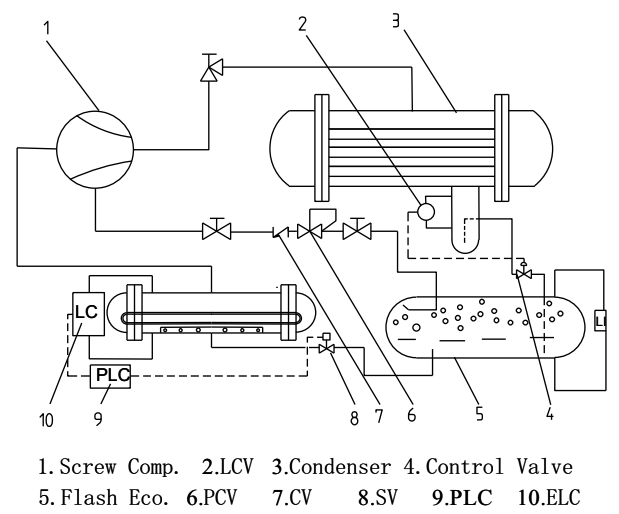

Figure 1. Flow chart of refrigeration system

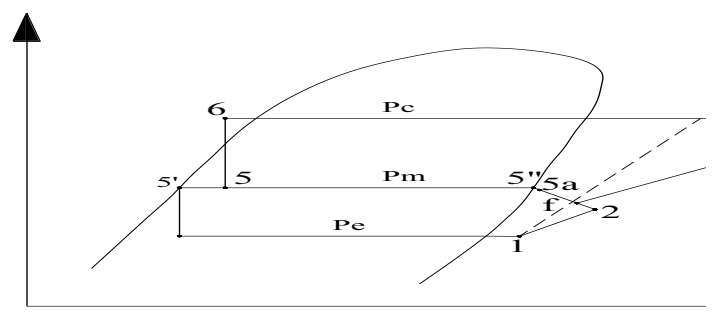

Figure 2. P-h of flash type economizer system

The screw compressor with gas supply port can be considered as a two-stage system compression process, and the P-h shown in Fig. 2. The compressor draws in the gas first. Then, the gas suction chamber in the compressor is separated from the suction port at the end of suction process, and the primitive volume chamber becomes an enclosed space [9]. After a short period of compression, the primitive volume chamber immediately connects with the gas supply port. At this position, the gas from the flash type economizer at pressure $\mathrm{P}_{\mathrm{m}}$ enters the compressor immediately. The opening of the gas supply port will increase gradually as the rotation of the screw, and more gas is drawn in, thus higher pressure is produced in the chamber. With the increase of the pressure in the chamber, the differential pressure and the amount of supply gas decreases. At the end of gas supply process, the pressure at the primitive volume chamber is $\mathrm{P}_{\mathrm{f}}$, which is less than $\mathrm{P}_{\mathrm{m}}$. In the screw compressor, the compression process is a continuous process. The gas in the gas supply chamber is at a relatively stable state, so the gas supply process is a rotating pressurization and adiabatic gas mixed combination process. When the gas supply port is separated from the suction port the second stage compression starts. In the beginning of compression, oil is sprayed into the compression chamber. Because the temperature of oil is higher than that of gas, so gas is heated by oil. At the end of compression, the temperature of gas is higher than that of oil, thus the compression process is a polytrophic compression process. On the $\mathrm{p}-\mathrm{h}$ graph, the slope of f-3 should be greater than the adiabatic compression process (f-3'). If the screw compressor internal pressure ratio is less than the external the pressure ratio, that is to say exhaust pressure (P3) is less than condensing pressure $(\mathrm{Pc})$, the exhaust process is approx isovolumic compression process. If the compressor internal pressure ratio is greater than the external pressure ratio, that is $\mathrm{P} 3>\mathrm{Pc}$, the exhaust process is constant volume expansion [10]. In short, the position of gas supply port and the oil temperature will influence the indicating efficiency of the second stage compression, change refrigerating capacity, compressor power and COP in a certain extent [11], [12].

\subsection{Determination of the parameters of primary compression process}

The supply port is added in the compressor rotor on the direction of the length of the screw, and the location of this port determines volume ratio. The pressure and temperature at the end of the primary compression are calculated by formula (1), (2) [13].

$$
\begin{aligned}
& P_{2}=P_{1}\left(\eta_{v 1} \varepsilon_{v 1}\right)^{n} \\
& T_{2}=T_{1}\left[\frac{P_{2}}{P_{1}}\right]^{\frac{n-1}{n}}
\end{aligned}
$$

Among them, $P_{1}$ : compressor suction pressure, $\mathrm{Pa}$.

$P_{2}$ : Pressure at the end of the primary compression, $\mathrm{Pa}$.

$T_{1}$ : Compressor suction temperature, $\mathrm{K}$.

$T_{2}$ : Temperature at the end of the primary compression, $\mathrm{K}$.

$\eta_{v 1}$ : Volume efficiency of the primary compression.

$\varepsilon_{v 1}$ : Volume ratio of the primary compression.

\subsection{Mass and energy balance of economizer}

For the flash type economizer, the gas mass and energy balance equation in the supply process are as follows:

$$
\begin{gathered}
q_{c}=q_{e}+q_{f} \\
q_{c} h_{5}=q_{e} h_{5^{\prime}}+q_{f} h_{5^{\prime \prime}}
\end{gathered}
$$

Among them, $q_{c}$ : Mass flow of the compressor exhaust, $\mathrm{kg} \mathrm{s}^{-1}$.

$q_{e}$ : Mass flow of evaporator, $\mathrm{kg} \mathrm{s}^{-1}$.

$q_{f}$ : Mass flow of the economizer supply gas, $\mathrm{kg} \mathrm{s}^{-1}$.

$h_{5}$ : Specific enthalpy of saturated liquid refrigerant in the flash type economizer, $\mathrm{kJ} \mathrm{kg}^{-1}$.

$h_{5 "}:$ Specific enthalpy of saturated refrigerant gas in the flash type economizer, $\mathrm{kJ} \mathrm{kg}^{-1}$.

$h_{5}$ : Specific enthalpy of sub-cooled liquid, $\mathrm{kJ} \mathrm{kg}^{-1}$. 


\subsection{Determination of the parameters for the supply process}

Supply process is an approximate isentropic and adiabatic process. Gas supply equation of per refrigerant suction volume, the energy equation of gas supply process, the specific volume equation and the specific entropy equation are shown as formula (5), (6), (7), (8) [11]:

$$
\begin{gathered}
\alpha=\frac{q_{f}}{q_{e}} \\
h_{2}+\alpha \cdot h_{5^{\prime \prime}}=(1+\alpha) h_{f} \\
v_{f}=v_{2} /(1+\alpha) \\
(1+\alpha) \cdot s_{f}=\alpha \cdot s_{5^{\prime \prime}}+s_{2}
\end{gathered}
$$

\section{Among them,}

$\alpha$ : Gas supply ratio of flash type economizer refrigerant system;

$v_{2}$ : Specific volume at the end of the primary compression, $\mathrm{m}^{3} \mathrm{~kg}^{-1}$.

$v_{f}$ : Specific volume at the end of the supply process, $\mathrm{m}^{3} \mathrm{~kg}^{-1}$.

$s_{f}$ : Specific entropy at the end of the supply process, $\mathrm{kJ}(\mathrm{kg} \cdot \mathrm{K})^{-1}$

$s_{2}$ : Specific entropy at the end of the primary compression, $\mathrm{kJ}(\mathrm{kg} \cdot \mathrm{K})^{-1}$.

$S_{5^{\prime \prime}}$ : Specific entropy of saturated gas at the economizer pressure, $\mathrm{kJ}(\mathrm{kg} \cdot \mathrm{K})^{-1}$.

\subsection{Exhaust temperature of compressor}

The compression process is a changeable compression process after the supply process, the exhaust temperature $\mathrm{T}_{3}$ is calculated as follows:

$$
T_{3}=T_{f}\left[\frac{P_{c}}{P_{f}}\right]^{\frac{n-1}{n}}
$$

\subsection{Refrigerating capacity and compression power}

The refrigerating capacity is calculated as follows:

$$
Q_{L}=q_{c}\left(h_{1}-h_{6}\right)
$$

For the compression power calculation:

$$
W=\frac{q_{e}\left[\left(h_{3}-h_{1}\right)+\alpha \cdot\left(h_{3}-h_{5^{\prime \prime}}\right)\right]}{\eta_{e} \eta_{d}}
$$

Among them, $\eta_{e}$ : Adiabatic efficiency of the compressor.

$\eta_{d}$ : Motor efficiency (including the transfer efficiency between the motor and the compressor).

In this paper, the theoretical displacement of the compressor is $650 \mathrm{~m}^{3} \mathrm{~h}^{-1}$. The refrigerating capacity, COP value of refrigeration unit, and compressor power are showed in Fig. 4. The curve is the theoretical calculation results at different economizer pressure when the suction pressure is $135 \mathrm{kpa}$ and exhaust pressure is $1370 \mathrm{kpa}$.

\section{Experimental}

Refrigerant unit experimental is completed in environmental simulation laboratory. The experimental devices include brine system and refrigerant system. Technical parameters and precision of experiment instruments are shown in Table 1.

Table 1. Experimental instruments and equipment.

\begin{tabular}{cccc}
\hline $\begin{array}{c}\text { The } \\
\text { serial } \\
\text { number }\end{array}$ & Name of equipment & $\begin{array}{c}\text { Technical } \\
\text { parameters }\end{array}$ & Precision \\
\hline 1 & Current transformer & $0 \sim 600 \mathrm{~A}$ & 0.2 level \\
\hline 2 & Digital power meter & $\begin{array}{c}5.0 \sim 500 \mathrm{~V} / \\
0.01 \sim 40 \mathrm{~A}\end{array}$ & 0.5 level \\
\hline 3 & $\begin{array}{c}\text { Electromagnetic } \\
\text { flowmeter }\end{array}$ & $0 \sim 100 \mathrm{~m}^{3} \mathrm{~h}^{-1}$ & $0.50 \%$ \\
\hline 4 & PT temperature sensor & $-60 \sim 60^{\circ} \mathrm{C}$ & A level \\
\hline 5 & Pressure sensor & $-50 \sim 2000 \mathrm{kPa}$ & $0.10 \%$ \\
\hline
\end{tabular}

The flash type economizer is applied in the refrigerating unit, using R290 as refrigerant, with the open type twin-screw compressor, the water-cooled shell and tube condenser, and half bundle evaporator.

The rotor diameter of the screw is $163.2 \mathrm{~mm}$. The length diameter ratio is 1.65 . The theoretical displacement of compressor is $640.7 \mathrm{~m}^{3} \mathrm{~h}^{-1}$. The throttling valve adopts Fisher LCV to control the refrigerant level of condenser. The pressure control valve controls the pressure of the economizer. Using PID, it can achieve the stability of the economizer pressure and liquid level at different load and pressure.

\section{Experimental data analysis}

At different supply pressure, the theoretical and experimental results of the unit capacity, power and COP are shown in Fig. 3. The experimental conditions are: evaporate at $-35 \pm 1{ }^{\circ} \mathrm{C}$, condensate at $40 \pm 1^{\circ} \mathrm{C}$, superheat $1{ }^{\circ} \mathrm{C}$ at the $100 \%$ load. The Fig shows that the unit capacity decreases with the increase of the economizer supply pressure, the same is true for compressor power. The Cal. capacity is about $96.7 \%$ to that of the Exp. capacity, the Cal. power is about $101.2 \%$, and the Cal. COP is about $95.5 \%$. So for the refrigeration unit with flash type economizer, the theoretical calculation results are basically consistent with the experimental data. Both to theoretical and experimental data, the refrigerant system COP is parabola distributed with the increase of gas supply pressure. COP increases first, then decreases, because of the reducing rate of refrigerating capacity is less than the rate of power when the supply pressure is closer to the suction pressure. And the opposite occurs 
when the supply pressure is closer to the exhaust pressure. As can be seen from Fig. 3, refrigerating capacity curve is approximate linear curve, and the power curve is about quadratic curve. So there must be an optimal supply pressure for flash type economizer system. Theoretical calculated COP reaches a peak at the pressure of 402.9 $\mathrm{kPa}$, and the experimental test is about $412 \mathrm{kPa}$. This shows that when the gas supply pressure is $2.98 \sim 3.05$ times of the compressor suction pressure, COP is the highest, and the gas supply port position is reasonable.

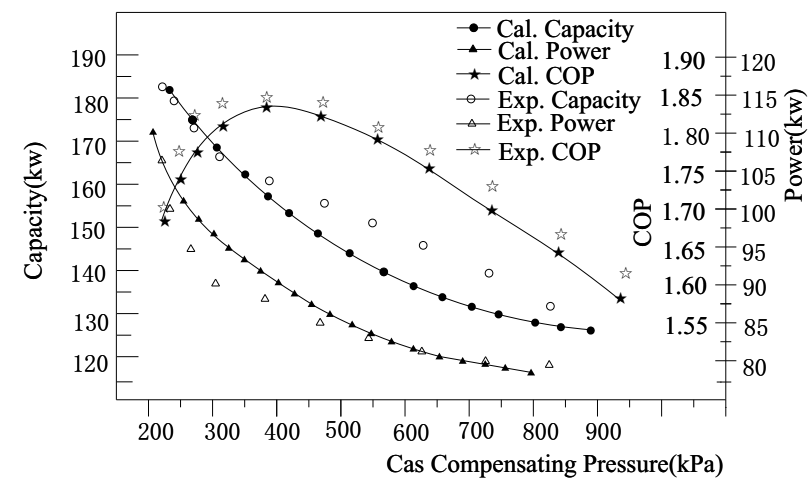

Figure 3. T\&E curve in different supply pressure

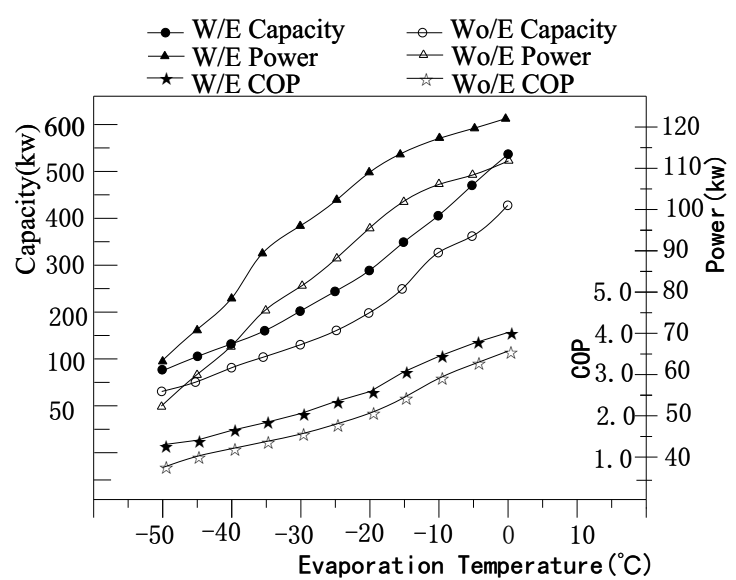

Figure 4. The thermal performance of different evaporation temperature

Flash type economizer has great impact on the performance of refrigeration unit. In two different working conditions (flash type economizer put into use and fall out of use), when the condensing temperature remains at $40^{\circ} \mathrm{C}$, the thermal performance (such as refrigerating capacity, shaft power and COP) at different evaporation temperature is shown in Fig. 4. Regardless of whether the economizer is put into use, with the increase of the evaporation temperature, the cooling capacity and the compressor shaft power will increase, and both are basic linear change. When evaporate at $-5^{\circ} \mathrm{C}$, the refrigerating capacity of the unit with flash type economizer increased by $30 \%$ than without the economizer, shaft power increased by $10 \%$, and the cop increased by $17.1 \%$. And when evaporate at $-50^{\circ} \mathrm{C}$, the refrigerating capacity of the unit with flash type economizer increased by $72 \%$, shaft power increased by $18 \%$, and the COP increased by $45.5 \%$. Experimental data show that the capacity and shaft power are greatly improved with the use of economizer. With the decrease of the evaporation temperature, the change rate of refrigerating capacity is greater than that of power. Because the COP of the unit with economizer is higher than without economizer, refrigeration performance of flash type economizer unit is obviously improved. In lower evaporation temperature, that is to say, compression ratio is higher, the greater the COP is. Therefore, in low-temperature refrigeration occasions, refrigerating units using flash type economizer can greatly improve the refrigerating capacity and cooling efficiency of the unit.

The change trend of refrigerating capacity and shaft power can be explained by theoretical analysis of refrigeration unit. With the change of air supply pressure, air supply flow is different. When the air supply port is more close to the suction chamber, supply pressure decreases, the gas supply flow increases, and the refrigeration capacity increases greatly. And the second stage compression section of the compressor will extend, the increasing amplitude of shaft power becomes large. When the air supply port is more close to the discharged port, supply pressure increases, the gas supply flow decreases, and the refrigeration capacity decrease greatly. And it will shorten the second stage compression section of the compressor, causing the increasing amplitude of shaft power becomes small. So the change trend of refrigerating capacity with supply pressure is the same as shaft power. With the increase of the supply pressure, the actual growth rate of polytrophic compression power will become large. Because of the injection of higher pressure gas into the compression chamber, more power will be consumed than the equivalent low pressure gas, thus cause the compressor shaft power growth rate becomes larger. However, with the gas flow becomes smaller the growth rate of theoretical adiabatic power will become lower. So there must exist an optimal supply pressure makes the most efficiency of the compressor. That is, the greatest ratio of theoretical adiabatic power to the actual polytrophic compression power.

The above experimental and theoretical analyses show that the low temperature cooling capacity and efficiency of refrigerating unit are improved obviously with the use of flash type economizer. With the use of flash type economizer system, the scope of low temperature refrigeration has been effectively expanded, and the operation reliability of refrigeration unit greatly improved.

\section{Conclusions}

This paper makes an experimental in thermo performance of refrigeration unit with flash type economizer using Refrigerant R290. The data show that, using the economizer can effectively improve the unit's cooling capacity and COP, so as to achieve the effect of saving energy. And when the compression ratio increases, the energy saving effect will be more significant.

The experimental data of the effect of supply pressure on the compressor refrigeration efficiency is consistent with theoretical analysis. For the refrigerating unit, there 
is an optimal point of economizer supply pressure. The actual supply pressure is slightly higher than this point.

For the application of environmental protection refrigerant R290 in refrigerating units, the technology is still in research stage, especially in the flash type economizer. In this paper, theoretical analysis have an important guiding significance for the design of refrigerating units with flash type economizer, and provide theoretical basis and practical support for improving the refrigerating unit's performance at low evaporation temperature in long-term reliable operation.

\section{Acknowledgment}

We gratefully acknowledge the support of this effort from the sponsors of the Refrigeration Technologies and Applications Laboratory of Nantong Shipping College.

\section{References}

1. X. Xu, Y. Hwang, R. Radermacher, Transient and Steady-State Experimental Investigation of Flash Tank Vapor Injection Heat Pump Cycle Control Strategy, Int. J. Refrig. 34,1922-1933 (2011)

2. J.H. Qiu, Design Analysis of Flash Type Economizer System for Ammonia as a Refrigerant, China Journal of Refrigeration, 32(2), 29-32 (2013)

3. Z.W. Xing, Screw Compressor - Theory, Design and Application, China Mechanical Industry Press, (2008)

4. J.J. Tian, Z. Zhang, Experimental Study on AirCooled Heat Pump on the Frosting Conditions, Refrigeration and Air Conditioning ( China Sichuan), 22 (1): 88-90 (2008)
5. L. Yang, W. Wang, Y.F. Bai, Influence of Economizer on Compression Refrigeration Cycle, Journal of Refrigeration (China), 4, 35-38+56 (2010)

6. Z. Sun, W. Chen, R. Yang, et al. Research of Refrigeration System with Ejector and Economizer, China Journal of Refrigeration, 1, 15-20 (2010)

7. C. Sun, Numerical Analysis and Study on R134a Applying in Gas Supply on Refrigeration System of Screw Compressor, Compressor Technology (China), 1, 33-34 (2012)

8. Analysis of Vapour Compression Refrigeration System with R404A, R407C and R410A, International Journal of Mechanical Engineering and Robitics Research, 2(1), 25-36

9. H.G. Wu, X.Y. Peng, Z.W. Xing, P.C. Su, Experimental Study On the Effects of Superfeed Pressure of Ecomizer on Twin-Screw Refrigeration Compressor Performance, Journal of Refrigeration (China), 4, 10-13 (2003)

10. L. Fu, G.L. Ding, C.L. Zhang, Z.J. Su, Development and Application of Screw-type Water Chiller Steadystate Simulation Model, HVAC, 35(5), 71-75 (2005)

11. H.H. Qin, Experimental Study on Performance of Air Cooled Heat Pump Device with Flashing System Economics, Journal of refrigeration (China), 34(5), 55-58 (2013)

12. Y.C. Li, Z.H. Cai, Y.F. He, et al. Study on Performance Characteristic of Heat Pump with Economizer, Journal of Refrigeration(China), 32(6), 17-19, 23, (2011)

13. Q.H. Chai, G.Y. Ma, Y. Jiang, J.J. Xia, et al. Thermodynamic Analysis of Scroll Compressor Refrigeration Cycle with Economizer, Journal of Tsinghua University (Natural Science Edition), 43(10), 1401-1404 (2003) 